\title{
Analisis Kemampuan Higher Order Thingking Skills (HOTS) Siswa Materi IPA Di Sekolah Dasar
}

\author{
Arrofa Acesta \\ PGSD Universitas Kuningan \\ arrofa.acesta@uniku.ac.id
}
APA Citation: Acesta, A. (2020). Analisis Kemampuan Higher Order Thingking Skills (HOTS) Siswa Materi IPA Di Sekolah Dasar. Quagga: Jurnal Pendidikan dan Biologi, 12(2), 170-175. doi: 10.25134/quagga.v12i2.2831.

Received: 26-05-2020

Accepted: 17-06-2020

Published: 01-07-2020

\begin{abstract}
Abstrak: Penelitian ini dilaksanakan untuk mengetahui kemampuan berpikir tingkat tinggi siswa pada pelajaran Ilmu Pengetahuan Alam (IPA) di sekolah dasar. Metode Penelitian yang digunakan adalah deskriptif dengan pendekatan kualitatif yaitu untuk mendeskripsikan kemampuan berpikir kritis, kreatif, dan pemecahan masalah secara kualitatif berdasarkan data kuantitatif. Sampel dalam penelitian ini adalah siswa kelas IV SDN Unggulan di Kuningan yang berberjumlah 23 siswa. Teknik pengumpulan data menggunakan analisis soal evaluasi harian IPA dan Kuisioner. Data yang telah terkumpul kemudian dianalisis menggunakan rumus deskriptif kualitatif. Hasil penelitian menunjukkan kemampuan berpikir kritis siswa pada pelajaran IPA di SD Kuningan indeks Persepsi siswa dalam aspek berpikir kritis termasuk katagori sering, aspek berpikir kreatif termasuk katagori sering dan aspek pemecahan masalah termasuk katagori jarang, berdasarkan data tersebut bahwa keterampilan berpikir tingkat tinggi sudah sering dilaksanakan. hasil analisis soal-soal evaluasi harian IPA menunjukkan soal yang menstimulasi kemampuan berpikir tingkat tinggi dan kemampuan berpikir tingkat rendah dari data hasil penelitian dapat menyimpulkan soal-soal IPA untuk mengembangkan HOTS masih rendah.
\end{abstract}

Kata Kunci: HOTS, Materi IPA

Abstract: This research was conducted to study the ability to think at a higher level in the Natural Sciences (IPA) lessons in elementary schools. The research method used is descriptive by using qualitative methods to describe the ability to think critically, creatively, and solve qualitative problems based on quantitative data. The sample in this study was 23 grade IV elementary students in Kuningan. The data assessment technique uses the daily IPA and Questionnaire evaluation question analysis. The data that has been collected is then developed using a qualitative descriptive formula. The results showed critical thinking skills in science lessons in Kuningan Kuningan index of student appreciation in critical aspects including frequent categories, aspects of creative thinking including frequent categories and aspects of problem solving including frequent categories, based on data related to the results of the analysis of daily science evaluation questions showing questions which stimulates higher-order thinking skills and low-level thinking skills from the data. The results of the study can overcome the problems of science to develop HOTS is still low.

Keywords: HOTS, Science Materials

\section{PENDAHULUAN}

Implementasi Kurikulum 2013 bertujuan untuk meningkatkan mutu kualitas pendidikan agar mampu berdaya saing menghadapi tantangan di era industri 4.0 sehingga menghasilkan generasi emas 2045 yang gemilang dari aspek pengetahuan sikap dan keterampilan. Penerapan kurikulum 2013 dalam rangka menyikapi tuntutan zaman yang semakin kompetetitif (Apandi, 2018:10).

Salah satu elemen perubahan pada kurikulum 2013 pada jenjang sekolah dasar adalah penguatan proses pembelajaran. Melalui proses pembelajaran yang baik diharapkan dapat meningkatkan kualitas pembelajaran lebih efektif, efisien, menyenangkan, dan bermakna, sehingga mampu meningkatkan kualitas pencapaian hasil belajar dan mengedepankan siswa berpikir kritis, tidak hanya menyampaikan konseptual maupun faktual. Hal ini di sesuaikan dengan kebutuhan peserta didik dimasa yang akan datang sehingga harus memiliki kecakapan berpikir untuk mencetak sumberdaya manusia yang berkualitas diantaranya memiliki kemampuan memecahkan masalah, berkomunikasi dan berpikir kritis (Acesta, 2019:3). Selanjutnya Acesta mengungkapkan Through education also students can interact with the environment to develop the abilities that exist in him. This ability can be in the form of 
cognitive abilities that hone knowledge, affective abilities to hone the sensitivity of feelings, and psychomotor abilities, namely the ability to do something. Through these three abilities a stuadent is expected to be able to become an individual who is ready to enter the world outside of school (Acesta, 2020:1-2).

Melalui penguatan proses pembelajaran diharapkan dapat meningkatkan kualitas pembelajaran lebih efektif, efisien, menyenangkan, dan bermakna, sehingga mampu meningkatkan kualitas pencapaian hasil belajar dan mengedepankan siswa berpikir kritis (tidak sekedar menyampaikan faktual). Pada kenyataannya masih banyak guru yang kurang faham tentang HOTS. Hal ini tampak pada rumusan indikator, tujuan, maupun kegiatan pembelajaran dan penilaiannya dalam rancangan pembelajaran yang dibuat dan pelaksanaan proses pembelajarannya. Guru harus mampu mengembangkan dan mengkonversikan dari pembelajaran yang masih bersifat Lower Order Thinking Skill (LOTS) menjadi Higher Order Thinking Skill (HOTS), dan ini harus sudah diawali sejak merancang Rencana Pelaksanaan Pembelajaran (RPP). Fanani, (2018:2).

Pentingnya optimalisasi kemampuan berfikir tingkat tinggi dalam pembelajaran didasarkan pada kenyataan bahwa sebagian siswa belum mampu untuk menghubungkan antara pengetahuan yang sudah dipelajari di sekolah dengan bagaimana cara mengimplementasikan dalam kehidupan nyata. Pembelajaran di sekolah dasar cenderung menekankan pada aspek hafalan, tanpa mengembangkan pemahaman yang mendalam untuk diaktualisasikan. Sehingga terkesan tidak konstektual, pembelajaran yang telah siswa lakukan seolah-olah tidak sama atau terpisah dari kehidupan nyata sehingga menjadikan pembelajaran tersebut tidak bermakna karena mereka tidak dapat menerapkan apa yang telah mereka pelajari apabila dihadapkan pada situasi berbeda yang mereka temui di luar kelas. Usmaedi (2017:83).

Pada hakekatnya keterampilan berpikir tingkat tinggi di sekolah dasar, merupakan kecakapan utama yang harus dimiliki seorang lulusan yang berkompeten sebagaimana tercantum dalam Permendikbud no. 54 tahun 2013 tentang standar kompetensi lulusan SD/MI "Memiliki kemampuan berpikir dan tindakan yang produktif dan kreatif dalam ranah abstrak dan konkret sesuai dengan yang ditugaskan kepadanya". Sehingga pembelajaran difokuskan pada pembentukan keterampilan berpikir tingkat tinggi yaitu menganalisis, mengevaluasi, dan mencipta atau kreativitas melalui pendekatan saintifik yang dikemas dalam pembelajaran tematik integratif.) keterampilan berpikir tingkat tinggi yakni berpikir kritis merupakan salah satu keterampilan terpenting bagi siswa di era globalisasi dan tranformasi yang mengarahkan siswa untuk dapat memilah informasi yang diperoleh secara luas, Fajriyah (2018:2).

Proses menganalisis, mengevaluasi, dan mengkreasi merupakan indikator dalam hots Higher Order Thinking Skills) Proses keterampilan berpikir tingkat tinggi diperoleh dari pengalaman siswa dalam mengikuti pembelajaran, siswa agar dapat mengkontruksi dan membangun suatu pengetahuan dalam dirinya sehingga memiliki kesadaran dalam proses pembelajaran. belajar yang seperti ini membuat siswa dapat berkembang dan memiliki kemampuan bernalar. Hal ini menunjukkan bahwa proses pembelajaran lebih pada kemampuan menggunakan konsep dan kemampuan mengembangkan keterampilan tingkat tinggi indikator untuk mengukur keterampilan berpikir tingkat tinggi (HOT) diantaranya adalah (1) menganalisis, meliputi menganalisis informasi yang masuk dan menstrukturisasi informasi menjadi bagian yang lebih kecil dalam menemukan pola dan hubungan, mampu mengenali serta membedakan faktor penyebab dan akibat, mengidentifikasi atau merumuskan pertanyaan; (2) mengevaluasi, meliputi: memberikan penilaian terhadap solusi, gagasan, dan metodologi dengan menggunakan kriteria standar yang ada untuk memastikan nilai efektivitas atau manfaatnya, membuat hipotesis, mengkritik dan melakukan pengujian, menerima atau menolak suatu pernyataan berdasarkan kriteria yang telah ditetapkan; (3) mengkreasi /mencipta, meliputi: membuat generalisasi suatu ide atau cara pandang terhadap sesuatu, merancang suatu cara untuk menyelesaikan masalah, mengorganisasikan unsur-unsur atau bagian-bagian menjadi struktur baru yang belum pernah ada sebelumnya. (Anugrahana: 144).

Berdasarkan pemaparan tersebut peneliti tertarik untuk fokus melaksanakan penelitian 
terkait dengan analisis kemampuan hots siswa. Adapun tujuan dari penelitian yang pertama untuk mendeskripsikan keterampilan berpikir kreatif siswa pada materi IPA di sekolah Dasar, Kedua untuk mendeskripsikan keterampilan berpikir kritis siswa, ketiga untuk mendeskripsikan keterampilan pemecahan masalah siswa.

\section{METODOLOGI PENELITIAN}

Metode Penelitian yang digunakan adalah deskriptif kualitatif. Secara metodologis, penelitian ini termasuk ke dalam jenispenelitian deskriptif kualitatif, yaitu laporan berdasarkan pendekatan kualitatif mencakup masalah deskripsi murni tentang program dan/atau pengalaman orang di lingkungan penelitian. Tujuan deskripsi ini adalah untuk membantu pembaca mengetahui apa yang terjadi di lingkungan di bawah pengamatan, seperti apa pandangan partisipan yang berada di latar penelitian, dan seperti apa peristiwa atau aktivitas yang terjadi di latar penelitian. Deskripsi ini ditulis dalam bentuk narasi untuk melengkapi gambaran menyeluruh tentang apa yang terjadi dalam aktivitas atau peristiwa yang dilaporkan (Emzir 2012:174).

Penelitian ini bertujuan mendeskripsikan keterampilan berpikir tingkat tinggi pada siswa kelas IV sekolah dasar Di Kuningan. Teknik pengumpulan data yang digunakan dalam penelitian ini analisis soal tes. Evaluasi harian untuk melihat keterampilan berpikir tingkat tinggi siswa. digunakan untuk menganalisis data dengan cara mendeskripsikan atau menggambarkan data.berdasarkan level kognitif dari Bloom (Ariyana 2018:6).

Tabel 1. Level Kognitif Bloom

\begin{tabular}{|c|c|c|}
\hline & Proses Kognit & \multirow{4}{*}{ LOTS } \\
\hline $\mathrm{C} 1$ & Mengingat & \\
\hline $\mathrm{C} 2$ & Memahami & \\
\hline $\mathrm{C} 3$ & Menerapkan & \\
\hline $\mathrm{C} 4$ & Menganalisis & \multirow{3}{*}{ HOTS } \\
\hline $\mathrm{C} 5$ & Mengevaliasi & \\
\hline C6 & Mencipta & \\
\hline
\end{tabular}

Kuisioner Persepsi siswa tentang penerapan higher order thinking skills di dalam pembelajaran. Isian kuisioner dikonversi menjadi data kuantitatif sebagai berikut; sangat sering skor 4, Sering skor 3, jarang skor 2 dan tidak pernah skor 1 .
Tabel 2. Indeks Persepsi Siswa Pembelajaran Berpikir Tingkat Tinggi

\begin{tabular}{llll}
\hline No & Aspek & $\begin{array}{l}\text { Item } \\
\text { pernyataan }\end{array}$ & jumlah \\
\hline 1 & Berpikir Kritis & 4 & 4 \\
\hline 2 & Berpikir kreatif & 4 & 4 \\
\hline 3 & $\begin{array}{l}\text { Pemecahan } \\
\text { masalah }\end{array}$ & 3 & 3 \\
\hline
\end{tabular}

Selanjutnya menentukan interval nilai untuk memasukan kategori persepsi siswa dengan menggunakan rumus:

Interval Skala $=\frac{m-n}{b}$

$\mathrm{m}=$ Angka tertinggi dalam skor jawaban

$\mathrm{n}=$ Angka terendah dalam nilai jawaban

$\mathrm{b}=$ Banyaknya kategori jawaban

berdasarkan rumus tersebut maka didapatkan interval skala sebagai berikut:

Tabel 3. Interval Skala Nilai

\begin{tabular}{ccc}
\hline Nilai Persepsi & $\begin{array}{c}\text { Indeks } \\
\text { interval }\end{array}$ & Kategori \\
\hline 1 & $1.00-1.75$ & Tidak Pernah \\
\hline 2 & $1.76-2.51$ & Jarang \\
\hline 3 & $2.52-3.27$ & Sering \\
\hline 4 & $3.28-4.00$ & $\begin{array}{l}\text { Sangat } \\
\text { Sering }\end{array}$ \\
\hline
\end{tabular}

Dimodifikasi dari Meilianawati (2019:44)

\section{HASIL PENELITIAN DAN PEMBAHASAN}

1. Keterampilan Berpikir Tingkat Tinggi (HOTS) di Sekolah Dasar

Hasil analisis kemampuan keterampilan berpikir tingkat tingggi (HOTS) dalam pembelajaran di sampaikan oleh guru di kelas berdasarkan pendapat siswa yang berjumlah 23 siswa. Kemampuan hots dilihat dari aktivitas guru dalam pembelajaran untuk menstimulasi kemunculan berpikir kritis, berpikir kreatif, dan pemecahan masalah. hasil penghitungan berdasarkan interval skala likert tidak pernah, jarang, sering dan sering sekali.

Tabel 4. Hasil Analisis Indeks Persepsi Siswa

\begin{tabular}{llll}
\hline No & Aspek & $\begin{array}{l}\text { Rata- } \\
\text { rata } \\
\text { Skor }\end{array}$ & Kategori \\
\hline 1 & $\begin{array}{l}\text { Berpikir } \\
\text { Kritis }\end{array}$ & 2.55 & Sering \\
& & & \\
\end{tabular}




\begin{tabular}{llll}
2 & Berpikir & 2.58 & Sering \\
& $\begin{array}{l}\text { Kreatif } \\
\text { Pemecahan } \\
\text { Masalah }\end{array}$ & 2.00 & Jarang \\
\hline
\end{tabular}

Berdasarkan tabel 1 tersebut, peneliti dapat menetapkan tingkat pencapaian kemampuan berpikir tingkat tinggi berdasarkan hasil penilaian pendapat siswa berdasarkan indeks pendapat siswa. Untuk lebih jelasnya dapat dilihat dalam bentuk grafik batang berikut ini.

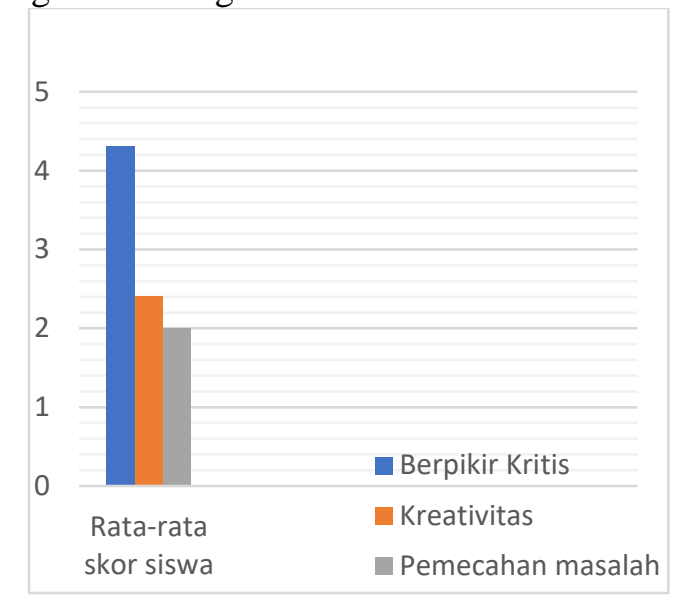

Gambar 1. Hasil Analisis Indeks Pesersepsi Siswa

Berdasarkan gambar 1, hasil analisis 23 siswa kelas IV bersama guru kelas dan peneliti membimbing siswa agar dapat menilai guru berdasarkan pendapat siswa dengan tidak merasa ada tekanan dari siapapun. Selanjutnya peneliti menghitung rata-rata setiap indikator keterampilan berpikir tingkat tinggi atau (HOTS) berdasarkan tiga indikator yaitu berpikir kritis, kreativitas dan pemecahan masalah. Berdasarkan tabel di atas bahwa persepsi siswa terhadap keterampilan Berpikir Tingkat Tinggi (HOTS) adalah untuk kriteria berpikir kritis (Critical Thinking) dengan skor rata rata adalah 2.55 termasuk kedalam katagori sering, sedangkan untuk kriteria kreativitas memiliki skor rata-rata adalah 2.58 termasuk katagori sering dan untuk pemecahan masalah (problem solving rata-rata skor adalah 2.00 termasuk kedalam katagori jarang. Selaras dengan hasil penelitian Meilianawati (2018:50) critical thinking memiliki skor rata-rata 2,75 berdasarkan persepsi siswa artinyanya bahwa kemampuan tersebut sering diterapkan oleh guru di dalam kelas. Untuk aspek Creativity memiliki skor 2,52 bahwa aspek kreatifitas sering diterapkan oleh guru di dalam kelas, selanjutnya hasil penelitian Wijayanti (2019:65) memaparkan bahwa indikator berpikir kritis ( critical thingking) dan problem solving skor rata-rata 3,22 termasuk kedalam kategori sering, sedangkan indikator creativity skor rata-rata 2,83 termasuk kategori sering. artinya bahwa aspek berpikir kritis, pemecahan masalah dan kreativitas sering diterapkan dalam pembelajaran di kelas, Selanjutnya hasil penelitian Ismawati (2019:71) analisis persepsi siswa terhadap pembelaharan HOTS adalah; aspek berpikir kritis dan pemecahan masalah 2.09, termasuk kategori jarang, aspek kreativitas 2,35 termasuk kategori jaranghal ini berarti bahwa pembelajarn yang di terapkan dikelas belum menstimulasi munculnya HOTS.

\section{Hasil Analisis Soal Evaluasi Harian}

Peneliti melakukan analisis terhadap soal-soal ulangan harian yang sudah dibuat oleh guru dan peneliti hanya menganalisis soal-soal yang berkaitan dengan muatan Ilmu Pengetahuan Alam, yang terdiri dari tema 6, 78 sub tema 1,2 dan 3 berdasarkan hasil analisis soal evaluasi harian yang berkaitan dengan muatan IPA dari 20 soal yang termasuk katagori keterampilan berpikir tinggi higher order thinking skills(hots) indikator soal taksonomi Bloom kategori C4, C5, C6 yaitu 5 soal atau $25 \%$ dan 15 soal atau $75 \%$ termasuk katagori keterampilan berpikir tingkat rendah / low order thinking skills (lots) indikator soal taksonomi Bloom kategori C1, C2 C3. Untuk lebih jelasnya dapat di lihat dalam bentuk diagram batang berikut;

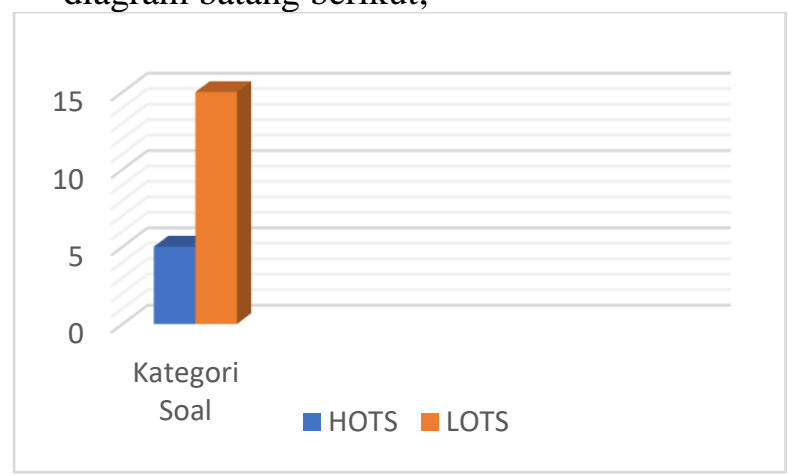

Gambar 2. Hasil Analisis Soal IPA 
Berdasarkan gambar 2, dapat disimpulkan bahwa masih rendahnya soal soal evaluasi yang menggunakan keterampilan berpikir tingkat tinggi atau higher order tinking skills (hots) yaitu hanya 5 soal saja dari 20 soal yang dianalisis. Selebihnya soal-soal yang termasuk kategori keterampilan berpikir rendah.

Hasil analisi soal IPA Wijayanti, (2019:58) menunjukkan bahwa soal -soal ujian masih didomonasi kriteria soal LOTS (Lower Order Thinking Skills) $73 \%$ dan soal ujian yang termasuk kriteria HOTS (Higher Order Thinking Skills) $27 \%$ dari 40 soal yang dianalisis, sedangkan Ismawati (2019:92) hasil analisis soal IPA menunjukkan $95 \%$ soal termasuk kriteria LOT dan $5 \%$ soal termasuk kategori HOTS dari 22 soal yang dianalisis, sehingga dapat disimpulkan berdasarkan berbagai hasil penelitian tersebut rendahnya soal-soal ujian yang berkategori HOTS sehinga sangat perlu adanya pelatihan bagi guru dalam menyusun soal ujian. Sehingga diharapkan dapat meningkatkan kualitas soal ujian.

\section{SIMPULAN}

Berdasarkan hasil penelitian maka dapat disimpulkan sebagai berikut:

1. ketiga aspek indikator higher order thinking skills, telah muncul dalam pembelajaran berdasarkan pendapat siswa bahwa aspek berpikir kritis, aspek berpikir kreatif sudah tercermin dan terlaksana dalam pembelajaran dan masuk kedalam kataagori sering, sedangkan aspek pemecahan masalah masuk kedalam katagori jarang

2. Hasil analisis soal evaluasi harian materi Ilmu Pengetahuan Alammenunjukkan bahwa hanya 5 soal atau $25 \%$ yang menunjukkan soal termasuk higher order thinking skills dan 15 soal atau $75 \%$

3. Berdasarkan hasil analisis soal evaluasi, masih rendahnya soal-soal yang termasuk kategori HOTS, sehingga diperlukan perbaikan dan peningkatan mutu/kualitas dalam menyusun soal-soal evaluasi agar kriteria soal HOTS lebih dominan.

\section{REFEERENSI}

Acesta, Arrofa. 2019. Pengaruh Model Pembelajaran Guided Discovery
Terhadap Kemampuan Berpikir Kritis Jurnal Dinamika IPA Sekolah Dasar. Universitas Negeri Jakarta.

Acesta, Arrofa. 2020. Development of Natural Science Learning Models Based on Multiple Inteligences to Improve Higher Order Thinking Skills in Elementary Schools. Journal of Physics: Conference $\begin{array}{lllll}\text { Series } & 1477 \quad \text { (2020) } & 042036 & \text { IOP }\end{array}$ Publishing doi:10.1088/17426596/1477/4/042036.

Ariyana, Yoki, Dkk. 2018. Buku Pegangan Pembelajaran Berorientasi pada Keterampilan Berpikir Tingkat Tinggi. Direktorat Jenderal Guru dan Tenaga Kependidikan Kementerian Pendidikan dan Kebudayaan, Jakarta.

Anugrahana, Andri. 2018. Tinjauan Deskriptif Penerapan Higher Order Thinking dan Problem-Based Learning Pada Mata Kuliah Geometri Berdasarkan Kemampuan Matematika Mahasiswa, Scholaria: Jurnal Pendidikan dan Kebudayaan, Vol. 8 No. 2, Mei 2018: 142-156 Universitas Sanata Dharma.

Apandi, Idris. 2018. Strategi Pembelajaran Aktif Abad 21 dan Hots. Samudra Biru, Yogyakarta.

Emzir. 2012. Metodologi Penelitian Pendidikan Rajawali Press. Jakarta.

Fanani, Ahmad, Kusmaharti Dian. 2018. Pengembangan Pembelajaran Berbasis Hots (Higher Order Thinking Skill) Di Sekolah Dasar Kelas V. Jurnal Pendidikan Dasar P-ISSN 2086-7433 EISSN 2549-5801 Universitas PGRI Adi Buana. Surabaya.

Fajriyah Khusnul, Agustini Ferina. 2018. Analisis Keterampilan Berpikir Tingkat Tinggi Siswa SD Pilot Project Kurikulum 2013 Kota Semarang. Jurnal Elementary School e-ISSN 2502-4264 Volume 5 nomor 1 Januari 2018 Pendidikan Guru Sekolah Dasar Universitas PGRI Semarang.

Ismawati Bernadeta Putri, 2019 Analisis Keterampilan Berpikir Tingkat Tinggi Dalam Pembelajaran Tematik Siswa Kelas IVTahun Ajaran 2018.2019, Skripsi Universitas Sanata Dharma. Yogyakarta.

Meilianawati Bernadeta Ika. 2019. Analisis Keterampilan Berpikir Tingkat Tinggi 
Pada Pembelajaran Tematik Kelas III. Skripsi Universitas Sanata Dharma. Yogyakarta

Usmaedi. 2017. Menggagas Pembelajaran Hots Pada Anak Usia Sekolah Dasar. JPSD Vol. 3 No. 1, Maret 2017 ISSN 2540909382, STKIP Setia Budhi Rangkas Bitung.

Wijayanti, Putri Nugraheni, 2019, Analisis Keterampilan Berpikitr Tingkat Tinggi Pada Pembelajaran Tematik Kelas V, Skripsi Universitas Sanata Dharma. Yogyakarta. 